\title{
The Mining Game: Um jogo para simular o processo de Mineração do algoritmo Proof of Work utilizado em Blockchain
}

\author{
Levi Almeida da Silva ${ }^{1}$, Hanna Arnoud Alves ${ }^{1}$, Jerffeson Teixeira de Souza ${ }^{2}$ \\ ${ }^{1}$ Bacharelado em Ciência da Computação - Universidade Estadual do Ceará (UECE) \\ Fortaleza - CE - Brasil \\ ${ }^{2}$ Programa de Pós-Graduação em Ciência da Computação - Universidade Estadual \\ do Ceará (UECE) \\ Fortaleza - CE - Brasil \\ \{levi.silva, hanna.arnaud\}@aluno.uece.br, jerffeson.souza@uece.br
}

\begin{abstract}
Blockchain encompasses in its definition many computing concepts, such as cryptography, networks, algorithms, among others. Transmitting or learning about this technology can be quite complicated. Therefore, to foster teaching strategies, use gamification to make players understand a little better about the mining process in Blockchain. This work discusses the elaboration and validation of a physical game that simulates the working algorithm known as Proof of Work in which miners receive a reward for reaching the specified objective.
\end{abstract}

Resumo. Blockchain engloba em sua definição muitos conceitos da computação, como criptografia, redes, algoritmos, entre outros. Transmitir ou aprender sobre essa tecnologia pode ser dificultoso. Portanto, para fomentar estratégias de ensino, utilizou-se da gamificação para fazer com que os jogadores compreendam um pouco melhor sobre o processo de Mineração em Blockchain. Este trabalho discorre sobre a elaboração e validação de um jogo físico que simula o funcionamento do algoritmo conhecido como Proof of Work (Prova de Trabalho) no qual os mineradores recebem recompensa ao atingir determinado objetivo.

\section{Introdução}

O aprendizado de um novo conteúdo utilizando os métodos tradicionais de ensino, pode não implicar que o estudante irá entender determinado assunto. Conforme [dos Santos Neto and Franco 2010], alunos que recentemente terminaram o ensino médio, podem apresentar problemas com relação à composição do conhecimento devido à forma das aulas ministradas ( expositiva com metodologias tradicionais). Sendo assim, uma das estratégias para mitigar tal revés é utilizar o conceito de Gamificação. Esse processo engloba um conjunto de métodos de engajamento de pessoas com foco em direcioná-las aos objetivos propostos [Alves 2015]. Dessa forma, essa estratégia de ensinoaprendizagem pode ser aplicada também ao ensino dentro da área da TI (Tecnologia da Informação), mais precisamente, sobre Blockchain. Essa tecnologia vem sendo utilizada por várias empresas, por possibilitar ampliação de ideação e liberdade para humano e máquina [Swan 2015].

Entretanto, os conceitos envolvidos na tecnologia Blockchain podem tornar-se complexos tanto para parte do público em geral, como para os próprios profissionais da TI 
[Silva 2018] dada a não trivialidade de determinados assuntos. Dessa maneira, o presente trabalho aplica a estratégia supracitada no desenvolvimento de um jogo visando auxiliar no entendimento de conceitos concernentes à tecnologia Blockchain. Esta, por sua vez, é uma cadeia sequencial de blocos interligados entre si. Cada bloco contém um conjunto de informações e antes de um bloco ser adicionado à cadeia, ele é validado por um processo matemático computacional denominado Mineração [da Silva Rodrigues 2017]. Por sua vez, Proof-of-Work é um algoritmo de consenso onde cada nó minerador busca uma solução para tal processo a fim de poder criar um novo bloco. Esse desafio consiste em encontrar, por tentativa e erro, um valor abaixo de um alvo pré-definido [Nakamoto 2019]. Quando o valor é encontrado, o minerador gera um novo bloco e esse alvo é ajustado a cada certo número de blocos gerados. Porém, essa repetida tarefa demanda poder computacional de cada minerador. Este artigo apresenta o The Mining Game, um jogo físico para auxiliar o aprendizado do Proof-of-Work em uma Blockchain. A próximas Seções apresentam o desenvolvimento do jogo, sua descrição, o processo de validação e por último as considerações finais acerca do trabalho realizado. As imagens e tabelas foram elaborada pelos autores.

\section{Metodologia}

O processo de desenvolvimento do The Mining Game se baseou no trabalho de [Pires et al. 2019] e ocorreu de acordo com as etapas a seguir, como ilustra a Figura 1.

Na primeira etapa, conforme a problemática apresentada na Seção 1, buscaram-se es-
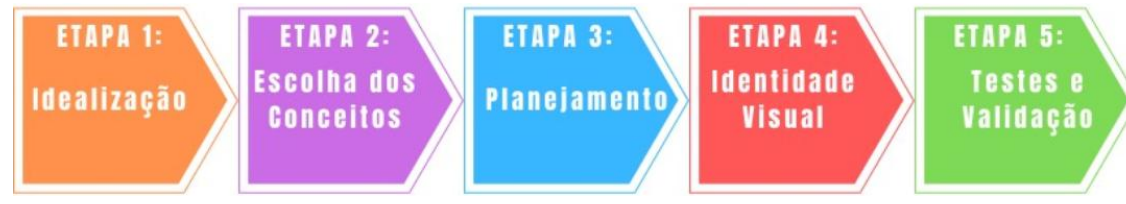

Figura 1. Etapas do desenvolvimento do The Mining Game

tratégias que facilitassem a compreensão da Blockchain, bem como algum assunto dentro da temática. A estratégia foi a gamificação e o assunto, Mineração. A próxima etapa consistiu em, dentro do assunto escolhido, selecionar alguns conceitos, e estes foram: Mineradores, Blocos e Tokens (recompensas). A escolha desses tópicos se deu por serem elementos essenciais para a compreensão do algoritmo. Na etapa 3, planejou-se a estrutura e regras do jogo, assim como as ferramentas auxiliadoras. Tais ferramentas foram: Tabuleiro, cartas e dados. A etapa seguinte compreende os layouts das ferramentas citadas anteriormente utilizando o Photoshop. O resultado se encontra na Figura 2. Na última etapa, o The Mining Game foi jogado por dez estudantes de graduação de algum curso de TI e afins, os quais têm idades entre 20 e 24 nos e estão entre o terceiro e oitavo período de seus respectivos cursos. Outras informações dos testes serão discutidos na Seção 4.

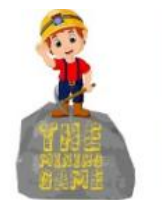

Logo do Jogo

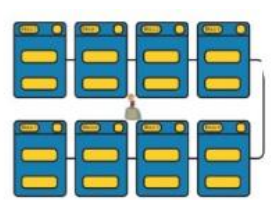

Tabuleiro

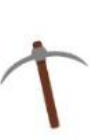

Carta-Picareta

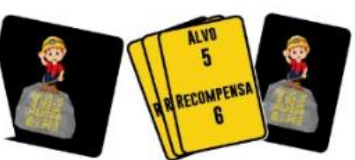

Carta-Bloco

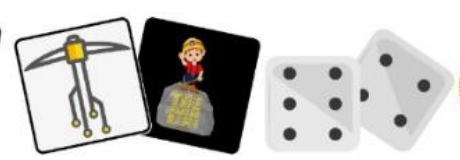

Poder computacional

Dados

Tokens

Figura 2. Elementos do The Mining Game 


\section{The Mining Game}

O jogo contém 150 cartas de Poder Computacional, 1 tabuleiro, 1 Carta-Picareta, 16 Carta-Bloco, 3 dados e 45 tokens. O objetivo do jogo é terminar a partida com o maior número de recompensas. Preparação: $O$ tabuleiro é mostrado e cada jogador recebe 30 cartas de Poder computacional. Início do Jogo: Os jogadores decidem entre si quem será o primeiro a jogar e este jogador recebe a Carta-Picareta indicando que este irá começar a rodada. Após isso, é retirada uma Carta-Bloco, que indica o alvo e a recompensa daquele bloco, e esta é colocada sobre o Bloco 0 do tabuleiro. Com os jogadores sabendo quais números precisam tirar e a recompensa caso acertem, incia a rodada de aposta. Ações dos Jogadores: O jogador que irá começar a rodada deve fazer a primeira aposta. Essa aposta consiste em usar suas cartas de Poder Computacional para jogar os três dados a fim de tirar um número menor que o alvo. Cada Poder Computacional significa o tanto de vezes que ele pode rolar os dados. Com o primeiro jogador fazendo a aposta, os demais decidem se vão apostar ou não. Após as decisões, iniciam as tentativas de acertar um número menor que o alvo. Os participantes jogam um de cada vez e rolam os três dados. Caso algum jogador acerte o valor, é dito que ele minerou o bloco e ele recebe a recompensa daquela rodada. Caso não tenha acertado, é passado a vez para o próximo jogador rolar os dados o número de vezes que ele colocou seu Poder Computacional. Quando alguém minera o bloco, é tirado uma nova Carta-bloco e o jogo se encerra quando o Bloco 7 é minerado.

Outras Regras: Caso nenhum jogador consiga minerar o Bloco, a Carta-Bloco volta para o pacote então é tirada outra Carta-Bloco. Os Poderes Computacionais apostados não voltam aos seus pertencentes.

\section{Validação}

Os jogadores foram divididos em dois grupos de três pessoas e um grupo de quatro pessoas em uma sala na Universidade Estadual do Ceará. As rodadas duraram em média 45 segundos quando o primeiro jogado minerava na primeira tentativa, e 2 minutos e 30 segundos quando todos os jogadores apostavam e o último participante recebia a chance de minerar, no caso dos testes, o quarto jogador. Cada grupo jogou quatro partidas e responderam um questionário seguindo a avalição de [Savi et al. 2011]. Tal modelo foi escolhido pois segundo [Petri et al. 2020] essa abordagem, entre modelos e frameworks de validação, se adequa para avaliar jogos de ensino no contexto da computação. Na composição do instrumento há 27 itens padronizados e organizados em três subcomponentes com suas respectivas dimensões. Os subcomponentes são Motivação, Experiência do Usuário, e Aprendizagem. Além disso, o modelo permite que seja elaborado um item específico sobre objetivo do jogo e conteúdos abordados. Assim, o item 28 consistiu do seguinte: "O jogo me fez ter noção de como funciona o processo de Mineração do algoritmo Proof-of-Work em Blockchain?".

Ademais, os jogadores avaliaram de forma online, através do Google Forms e atribuíram notas de 1 (discordo totalmente) a 5 (concordo totalmente) de acordo com a escala Likert, do item 1 ao 24. Do item 25 em diante, 1 significava "pouco" e 5 "muito". As tabelas 1, 2 e 3 apresentam as notas dos itens correspondentes aos subcomponentes supraditos, além de suas respectivas médias.

Levando em consideração os subcomponentes que as perguntas abordam, a Motivação teve a maior média, cerca de 4,15. O The Mining Game tem um resultado considerável nesse quesito devido à abstração que gera do funcionamento do algoritmo, visto que a maior nota desse subcomponente foi com relação aos jogadores se sentirem 
Tabela 1. Escala da Avaliação proposta por Savi com as médias obtidas na análise para o subcomponente Motivação

\begin{tabular}{|c|l|c|c|}
\hline$\#$ & \multicolumn{1}{|c|}{ Item } & Dimensão & Nota \\
\hline 1 & O design do jogo é atraente. & Atenção & 4,29 \\
\hline 2 & Houve algo interessante no início do jogo que capturou minha atenção. & Atenção & 4,14 \\
\hline 3 & A variação (forma, conteúdo ou de atividades) ajudou a me manter atento ao jogo. & Atenção & 4,43 \\
\hline 4 & O conteúdo do jogo é relevante para os meus interesses. & Relevância & 4,29 \\
\hline 5 & O funcionamento deste jogo está adequado ao meu jeito de aprender. & Relevância & 4,43 \\
\hline 6 & O conteúdo do jogo está conectado com outros conhecimentos que eu já possuía. & Relevância & 4,14 \\
\hline 7 & Foi fácil entender o jogo e começar a utilizá-lo como material de estudo. & Confiança & 4,14 \\
\hline 8 & Ao passar pelas etapas do jogo senti confiança de que estava aprendendo. & Confiança & 4,57 \\
\hline 9 & $\begin{array}{l}\text { Estou satisfeito porque sei que terei oportunidades de utilizar na prática coisas que } \\
\text { aprendi com o jogo. }\end{array}$ & Satisfação & 3,57 \\
\hline 10 & É por causa do meu esforço pessoal que consigo avançar no jogo & Satisfação & 3,57 \\
\hline \multicolumn{2}{|c|}{ Média } & $\mathbf{4 , 1 5}$ \\
\hline
\end{tabular}

Tabela 2. Escala da Avaliação proposta por Savi com as médias obtidas na análise para o subcomponente Experiência de Usuário

\begin{tabular}{|c|l|c|c|}
\hline$\#$ & \multicolumn{1}{|c|}{ Item } & Dimensão & Nota \\
\hline 11 & $\begin{array}{l}\text { Temporariamente esqueci as minhas preocupações do dia-a-dia, fiquei totalmente } \\
\text { concentrado no jogo. }\end{array}$ & Imersão & 3,14 \\
\hline 12 & Eu não percebi o tempo passar enquanto jogava, quando vi o jogo acabou. & Imersão & 3,43 \\
\hline 13 & $\begin{array}{l}\text { Me senti mais no ambiente do jogo do que no mundo real, esquecendo do que } \\
\text { estava ao meu redor. }\end{array}$ & Imersão & 3 \\
\hline 14 & Pude interagir com outras pessoas durante o jogo. & Interação Social & 4,57 \\
\hline 15 & Me diverti junto com outras pessoas. & Interação Social & 4,43 \\
\hline 16 & $\begin{array}{l}\text { O jogo promove momentos de cooperação e/ou competição entre as pessoas que } \\
\text { participam. }\end{array}$ & Interação Social & 4,57 \\
\hline 17 & $\begin{array}{l}\text { Este jogo é adequadamente desafiador para mim, as tarefas não são muito fáceis } \\
\text { nem muito difíceis. }\end{array}$ & Desafio & 3,14 \\
\hline 18 & $\begin{array}{l}\text { O jogo evolui num ritmo adequado e não fica monótono - oferece novos obstáculos, } \\
\text { situações ou variações de atividades. }\end{array}$ & Desafio & 3,29 \\
\hline 19 & Me diverti com o jogo. & Divertimento & 3 \\
\hline 20 & Quando interrompido,fiquei desapontado que o jogo tinha acabado. & Divertimento & 3 \\
\hline 21 & Eu recomendaria este jogo para meus colegas & Divertimento & 4 \\
\hline 22 & Gostaria de utilizar este jogo novamente & Competência & 4,29 \\
\hline 23 & Consegui atingir os objetivos do jogo por meio das minhas habilidades. & Divertimento & 3,43 \\
\hline 24 & Tive sentimentos positivos de eficiência no desenrolar do jogo & Competência & 3,86 \\
\hline & & & $\mathbf{3 , 6 5}$ \\
\hline
\end{tabular}

Tabela 3. Escala da Avaliação proposta por Savi com as médias obtidas na análise para o subcomponente Aprendizagem

\begin{tabular}{|c|l|c|c|}
\hline$\#$ & \multicolumn{1}{|c|}{ Item } & Dimensão & Nota \\
\hline 25 & $\begin{array}{l}\text { Quanto você acha que o jogo contribuiu para sua aprendizagem na disciplina? } \\
\text { (O assunto abordado). }\end{array}$ & $\begin{array}{c}\text { Aprendizagem } \\
\text { de Curto Termo }\end{array}$ & 4,14 \\
\hline 26 & $\begin{array}{l}\text { Quanto eficiente o jogo foi para sua aprendizagem, comparando-o com outras } \\
\text { atividades da disciplina? }\end{array}$ & $\begin{array}{c}\text { Aprendizagem } \\
\text { de Curto Termo }\end{array}$ & 4,14 \\
\hline 27 & $\begin{array}{l}\text { Você acha que a experiência com o jogo vai contribuir para seu desempenho na } \\
\text { vida profissional? }\end{array}$ & $\begin{array}{c}\text { Aprendizagem } \\
\text { de Longo Termo }\end{array}$ & 3,71 \\
\hline \multicolumn{2}{|c|}{ Média } & $\mathbf{4 , 0 0}$ \\
\hline
\end{tabular}

confiantes de que estavam adquirindo conhecimento de acordo que passavam as etapas. Outro destaque é sobre a maneira que o conteúdo ajudou os participantes a ficarem mais atentos no jogo. Isso pode ser justificado, pois o próximo a jogar tem a opção de tomar 
suas decisão baseada na jogada anterior.

Com relação à Experiência do Usuário, a média foi 3,65. Dado que o jogo não oferece tantas ações para os jogadores escolherem, pode-se chegar a um momento em que se torna repetitivo, porém por mais que essa seja a menor nota entre os subcomponentes os usuários, em geral, jogariam novamente. A nota do subcomponente Aprendizagem, foi próximo de 4,00. Essa nota representa que a atividade se sair melhor do que atividades de disciplinas que já abordaram o assunto. Vários fatores podem ter gerado a nota mais baixa desse subcomponente, desde os jogadores não trabalharem com a tecnologia, ou o jogo não ser tão profundo para tal assunto. Contudo, essa nota não foi tão baixa, portanto, pode-se inferir que algum aprendizado será útil. A nota com relação à última pergunta, sobre se o jogo cumpriu com o objetivo principal, foi unânime entre os participantes, nota 5,00. Assim comprova-se que apesar de algumas notas relativamente baixas em outros itens, a noção de como o Proof Of Work funciona é obtida.

\section{Considerações finais}

Blockchain é uma tecnologia que está sendo usada para diferentes aplicações, sendo assim, a busca por conhecer essa abordagem pode ser útil. Por isso, a partir da percepção de novas formas de transmitir ou adquirir conhecimento, foi buscado facilitar tais processos através da gamificação. O The Mining Game foi desenvolvido para ser uma ferramenta apropriada nessas etapas. As notas atribuídas na validação reforçam que para quem jogou, foi proveitoso, principalmente quando perguntado se a noção do Proof-of-Work foi obtida, pois todos os jogadores deram a nota máxima. É válido também ressaltar que os jogos educativos exercem um papel importante no processo de ensino-aprendizagem, devido sua atração. Como trabalhos futuros, pretende-se trabalhar novos conceitos e regras nas próximas versões do jogo, bem como validá-lo de acordo com instrumentos de avaliações pertinente a época que este for produzido.

\section{Referências}

Alves, F. (2015). Gamification: Como criar experiências de aprendizagem engajadoras. DVS editora.

da Silva Rodrigues, C. K. (2017). Sistema bitcoin: uma análise da segurança das transações. iSys-Brazilian Journal of Information Systems, 10(3):5-23.

dos Santos Neto, E. and Franco, E. S. (2010). Os professores e os desafios pedagógicos diante das novas gerações: considerações sobre o presente e o futuro. Revista de Educação do COGEIME, 19(36):9-25.

Nakamoto, S. (2019). Bitcoin: A peer-to-peer electronic cash system. Technical report, Manubot.

Petri, G., von Wangenheim, C. G., and Borgatto, A. F. (2020). Meega+: Um modelo para a avaliação de jogos educacionais para o ensino de computação. Revista Brasileira de Informática na Educação, 27(03):52.

Pires, F., Teixeira, K., Pessoa, M., and Lima, P. (2019). Desenvolvendo o pensamento computacional através da máquina de turing: o enigma do curupira. In Anais do XXVII Workshop sobre Educação em Computação, pages 523-532. SBC.

Savi, R., Wangenheim, C., and Borgatto, A. (2011). Um modelo de avaliação de jogos educacionais na engenharia de software. Anais do XXV Simpósio Brasileiro de Engenharia de Software (SBES 2011), São Paulo.

Silva, M. P. (2018). A segurança da democracia e a blockchain. Projeção, Direito e Sociedade, 9(1):119138.

Swan, M. (2015). Blockchain: Blueprint for a new economy. "O’Reilly Media, Inc.". 